\title{
Michael Basse, Entmachtung und Selbstzerstörung des Papsttums (1302-1414)
}

Leipzig : Evangelische Verlagsanstalt (Kirchengeschichte in Einzeldarstellungen II/1), 2011, 284 p., 28,00€.

\section{Andreas Willershausen}

Traducteur : Audrey Dauchy

\section{OpenEdition Journals}

Édition électronique

URL : http://journals.openedition.org/ifha/8413

DOI : 10.4000/ifha.8413

ISSN : 2198-8943

Éditeur

IFRA - Institut franco-allemand (sciences historiques et sociales)

Référence électronique

Andreas Willershausen, « Michael Basse, Entmachtung und Selbstzerstörung des Papsttums (1302-

1414) », Revue de l'IFHA [En ligne], Date de recension, mis en ligne le 01 février 2016, consulté le 22 septembre 2020. URL : http://journals.openedition.org/ifha/8413; DOI : https://doi.org/10.4000/ifha. 8413

Ce document a été généré automatiquement le 22 septembre 2020

(CIFHA 


\section{Michael Basse, Entmachtung und Selbstzerstörung des Papsttums (1302-}

\section{4)}

Leipzig : Evangelische Verlagsanstalt (Kirchengeschichte in

Einzeldarstellungen II/1), 2011, 284 p., 28,00€.

\section{Andreas Willershausen}

Traduction : Audrey Dauchy

L'histoire de la papauté au XIV siècle était considérée par les historiens de l'Église comme un temps de déclin spirituel et moral de l'administration de l'Église médiévale. La «curie romaine" établie à Avignon s'est distinguée en premier lieu par une centralisation et une fiscalisation à l'échelle européenne de l'attribution des ordres majeurs, contre l'opposition des chapitres cathédraux et des couvents. Le clergé curial français, majoritairement de formation juridique, a favorisé en fin de compte le développement d'Églises nationales et des idées conciliaristes par l'établissement de sanctions ecclésiastiques, individuelles et collectives, dans la mise en œuvre de sa politique fiscale. Cette question est traitée sous un angle politique par les auteurs des synthèses les plus récentes, encore parfois par le prisme de l'image, réfutée par la recherche française (Mollat, Guillemain, Favier), d'une dépendance d'une papauté d'Avignon à l'égard de la " captivité babylonienne » (Pétrarque) des rois de France. Les médiévistes allemands comme Franz J. Felten ou Stefan Weiß ont montré l'indépendance politique (et religieuse) de certains papes, ou ont mis en évidence la coopération financière, économique et même politique avec les Valois. Les spécialistes de la diplomatie et du conflit ont souligné l'importance des papes en tant que médiateurs dans la guerre de Cent Ans (1337-1453); la chercheuse norvégienne Eldbjœrg Haug a montré de nouveaux aspects de la centralisation papale à travers l'exemple de l'imprégnation de la Scandinavie par la Pénitencerie apostolique.

Un manuel plus récent sur le XIV e siècle de la collection Kirchengeschichte in Einzeldarstellungen (1978-2012, 39 tomes) de la maison d'édition Evangelische Verlagsanstalt, qui se présente comme un "ouvrage de référence pour les études " 
(http://www.eva-leipzig.de), doit aussi être apprécié à sa juste valeur au regard de l'esquisse de la pluralité des modèles d'interprétation. Le choix du titre Entmachtung und Selbstzerstörung des Papsttums (1302-1414) - « Dépossession de pouvoir et destruction de la papauté par elle-même (1302-1414)» - peut surprendre chez un éditeur protestant. Un titre si partisan devrait être de nature à renforcer des représentations de l'histoire problématiques, voire démodées, ou à leur donner naissance. Concernant le plan, Michael Basse ordonne son volume en six chapitres principaux (1. Das Papsttum in Avignon ; 2. Ordensgemeinschaften und Laienbewegungen ; 3. Die Kirche vor den Problemen von Armut und Reichtum; 4. Frömmigkeit und Häresien angesichts der Pestepidemien; 5. Christentum, Judentum und Islam ; 6. Das Abendländische Schisma), que l'auteur précise par une synthèse d'histoire événementielle (par exemple, 1. A. Die Papstkirche zwischen Avignon und Rom), le contexte historique structurel (1.B. Der Ausbau der Amtskirche), et des études de cas (1.C. Nationalkirchliche Tendenzen). Il faut souligner positivement que la présence de notes de bas de page comprenant une bibliographie actuelle et internationale avec des indications précises ne va plus de soi dans les manuels. Seules quelques monographies spécialisées (par exemple, les travaux de Stefan Weiß en histoire économique) n'ont pas été prises en considération. Il manque certes d'exposés didactiques, comme ceux de récentes collections où la mise en évidence et l'éclaircissement de concepts importants sont devenus usuels (par exemple dans la collection Geschichte Kompakt de la WBG), mais ce manque est aisément compensé par les parfaites explications de l'auteur dans le texte même, comme: Die Annaten, $d$. $h$. die Einkünfte einer Pfründe im ersten Jahr... «Les annates, c'est-à-dire les revenus de la première année d'un bénéfice... ».

Sur le plan du contenu, Basse suit parfois des modèles d'interprétation contestables, tels que la prétendue dépendance de Jean XXII à l'égard des derniers Capétiens, faibles en réalité, et de leur successeur Philippe VI de Valois, qui est plus affirmée qu'expliquée clairement, ou encore la prise de position du pape dans les négociations de paix anglofrançaises, attestée selon l'auteur. Des exemples analogues de cette thèse, poursuivie dans l'ouvrage entier, d'une Église du pape qui est "dépossédée de son pouvoir » par une influence extérieure, et plus précisément «se détruisant elle-même " par une centralisation rigoureuse, se retrouvent dans plusieurs chapitres (surtout 1. B./C).

$\mathrm{Au}$ contraire, la présentation détaillée par Basse du développement interne des ordres monastiques, des mouvements hérétiques, laïques ou de pauvreté au Bas Moyen Âge se révèle être incontestablement un point fort. Le grand atout du volume correspond parfaitement au multiperspektivischen Verknüpfung der Kirchengeschichte mit der Gesellschafts- und Kulturgeschichte (« lien aux multiples perspectives entre l'histoire de l'Église et l'histoire de la société et de la culture ») envisagé par l'auteur dans la préface. Le chapitre 6, Das Abendländische Schisma ("Le Grand Schisme d'Occident ») qui comble en partie l'absence de la partie $7 \mathrm{~b}$ à paraître de la nouvelle édition du Gebhardt. Handbuch der Deutschen Geschichte, est particulièrement recommandable pour l'enseignement universitaire. À l'aide des théories corporatistes canoniques d'Einheit der Kirche als Leib Christi (« unité de l'Église en tant que corps du Christ») (p. 165) du Haut Moyen Âge, fondements du conciliarisme, et des exemples d'initiatives de réforme monastique (2.A.1.), Basse souligne que les phénomènes d'Entmachtung und Selbstzerstörung des Papsttums (« dépossession de pouvoir et destruction de la papauté par elle-même ») constitueraient déjà au XIV siècle les premiers signes de la Réforme. Cette conclusion aurait, à vrai dire, plutôt dû être insérée dans le tome suivant sur le $\mathrm{XV}^{\mathrm{e}}$ siècle de la même collection en raison de l'ouverture institutionnelle de l'Église du 
pape dans la phase préparatoire du concile de Constance. Le volume, qui malgré quelques critiques ciblées est d'une lecture profitable, est complété par une liste de sources et une bibliographie judicieuses, par un tableau chronologique synoptique, ainsi que par un index des personnes et des choses concis. On pourrait souhaiter pour les éditions futures un titre moins provocateur, en ce qu'il rétrécit les perspectives.

Vous trouverez la table des matières ici : http://d-nb.info/1016516754/04.

INDEX

Index chronologique : Moyen Âge

Thèmes : Histoire des États et des pouvoirs, Histoire religieuse

\section{AUTEURS}

ANDREAS WILLERSHAUSEN

Universität Gießen 